Check for updates

Cite this: RSC Adv., 2019, 9, 19680

\title{
Experimental investigation on strength development of lime stabilized loess
}

\author{
Liang Jia, ${ }^{a}$ Jian Guo, ${ }^{a}$ Zhidong Zhou, (D) ${ }^{\text {b }}$ Yong Fuc and Kai Yao (D) *c
}

Lime stabilization has been widely used in pavement subbases and ground improvement, but the investigation of the mechanical properties and the microstructure of lime stabilized loess is still insufficient. In this study, the effects of lime content, porosity and curing time on the strength development of lime stabilized loess were investigated through a series of unconfined compression tests. The microstructure of lime stabilized loess with different curing time was also investigated by scanning electron microscopy (SEM). Experimental results revealed that the curing time had a significant effect on the unconfined compressive strength (UCS) of lime stabilized loess. For a curing time of no more than 7 days, the influence of lime content on the UCS of stabilized loess was not very obvious. A lime content of around $16 \%$ led to the maximum UCS within the range of lime content investigated. However, for longer curing periods (like 28 and 90 days), the UCS of stabilized loess tends to increase with the lime content. For constant lime content, the UCS of stabilized loess decreased almost linearly with the increase of porosity. Correlation of UCS with lime content, porosity and curing time was also developed. In addition, the variations in microstructure are analyzed to reveal the strength development mechanism of lime stabilized soil.

rsc.li/rsc-advances

\section{Introduction}

Loess is a widespread problematic soil in China due to its unfavorable engineering characteristics, such as collapsibility, erosion, and friability. ${ }^{\mathbf{1 - 6}}$ Without proper improvement of loess, some severe issues may be encountered in engineering practices, such as landslides, ground fissures and land subsidence. $^{7-13}$ Therefore, stabilization of loess by cementitious materials has been commonly adopted in pavement base layers and road subgrades. ${ }^{\mathbf{1 4 - 2 3}}$

Some previous studies showed that the addition of lime can significantly improve the engineering properties of soft soils. Harichane et al. studied the effect of lime on the physical and mechanical characteristics of cohesive soils, such as plasticity index, maximum dry density, optimum moisture content and UCS. It was shown that an increase in lime content resulted in decreasing of plasticity index and maximum dry density, while the optimum moisture content and UCS will increase with the lime content. ${ }^{24}$ Le Runigo et al. conducted a study on the durability of lime-treated silty soil with different lime content under long-term hydraulic conditions. Their results indicated that the shear strength and durability was related to the

${ }^{a}$ College of Civil Engineering, Lanzhou University of Technology, 730050, P. R. China. E-mail: jialiang1949@163.com; 1160536027@qq.com

${ }^{b}$ Department of Civil and Environmental Engineering, Washington State University, Pullman, WA 99164-2910, USA. E-mail: zhidong.zhou@wsu.edu

'Department of Civil and Environmental Engineering, National University of Singapore, 117576, Singapore.E-mail: fuyong@u.nus.edu; yaokai@u.nus.edu permeability of the treated soil, and the shear strength decreased significantly once the soil was soaked in water. Also, when the lime content was beyond the optimum lime content regarding dry density, the mixture exhibited better homogeneity and durability. ${ }^{25}$ Jha et al. investigated the influence of various lime contents on the strength and volume change behavior of lime stabilized soil. They found that the pozzolanic reaction in lime stabilized soil induced the formation of flocculated fabric, and the cementation products significantly reduced the compressibility and increased the strength of soil. ${ }^{26}$ Gao and Qian investigated the effect of lime treatment on the hydraulic conductivity of the stabilized soil, which indicated that the addition of lime could result in a decrease of hydraulic conductivity of loess at the same dry density. ${ }^{\mathbf{1 2}}$

The water to binder ratio plays a key role in controlling the strength of stabilized soil. ${ }^{27,28}$ To establish a methodology for quantifying the influence of the lime content and porosity on the UCS of lime stabilized soil, numerous studies were performed by Consoli et al. The results indicated that the UCS increased proportionally with the increase of lime content, but decreased with increasing porosity. ${ }^{29-31}$ Moreover, the void/lime ratio adjusted by an exponent was proved to be an appropriate parameter to assess the UCS of lime stabilized soil. Consoli et al. also confirmed the feasibility of the control parameter for the target strength of soil-fly ash-lime mixtures. ${ }^{32-34}$

Loess is remarkably different from other types of soils in terms of physicochemical and mechanical properties. It is porous and typically non-stratified, with a pale yellow or buff 


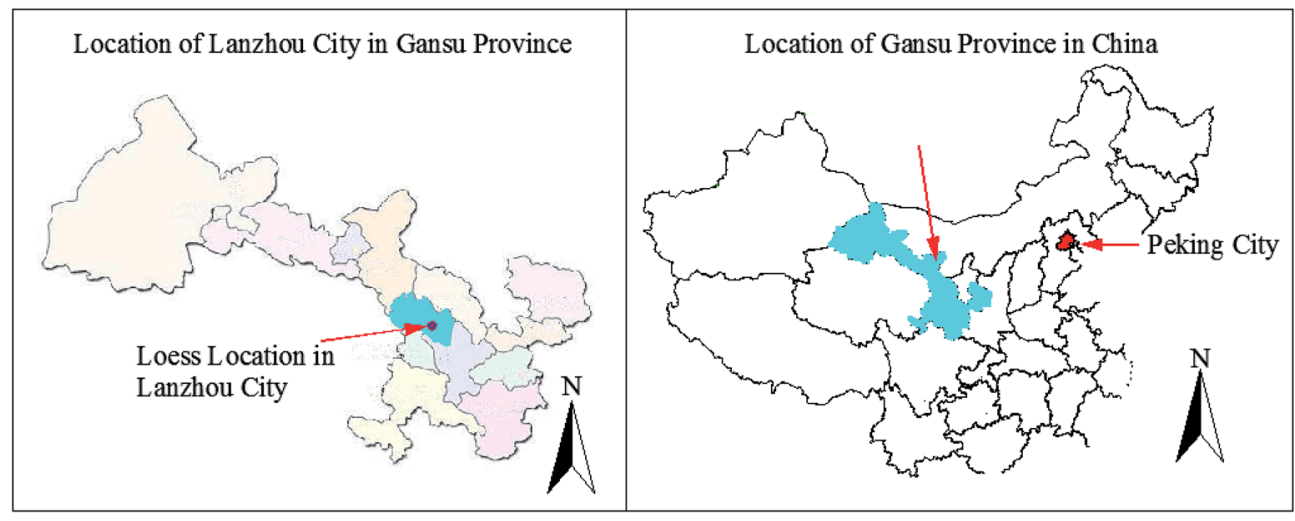

Fig. 1 Location of loess in this study.

colour. It contains a large number of angular silt grains and carbonate. In term of mechanical properties of loess, it is friable and slightly coherent. It would fail and cleave when meeting with moisture, which is called collapsibility. ${ }^{35}$ Loess is mainly distributed along with the Yellow River areas of China. The total distribution area is about $630000 \mathrm{~km}^{2}$, which is about $6.3 \%$ of the total land area of China. ${ }^{36}$ In recent decades, numerous of geotechnical engineering projects have been carried out in the Loess Plateau of China, ${ }^{1}$ so loess is a widely used construction and building material due to the limitation of other soil sources. Given the various unfavourable characteristics of loess and the aforementioned effective functions of lime, lime is a favourable option of stabilizer to improve the mechanical properties of loess in this region.

This paper aims to quantify the influence of lime content, porosity and curing time on the strength properties of lime stabilized loess. The scanning electron microscope (SEM) is also conducted to investigate the microstructure of lime stabilized loess with various curing time.

\section{Materials and experimental program}

\subsection{Materials}

The loess was obtained from a foundation pit located in Lanzhou City, China (Fig. 1). To ensure its homogeneity, the collected loess was air-dried, then crushed by a wooden hammer, and thereafter passed through the sieve with $0.5 \mathrm{~mm}$ opening size. After that, a serious of experiments were carried out to determine the physical properties of loess. Specific gravity of loess was obtained using the pycnometer method in accordance with ASTM D854 (2014). ${ }^{37}$ Atterberg limits of loess were measured through the fall cone test by following the Chinese standard procedures GB/ T50123 (1999). ${ }^{38}$ The physical properties of loess are summarized in Table 1. The lime was an industrial hydrated lime that produced by Hengwang Environmental Protection Company in Shandong Province, China. The lime was very fine and contained more than $98 \%$ of particles passing
Table 1 Physical properties of loess

\begin{tabular}{ll}
\hline Properties & Values \\
\hline Liquid limit & $24.67 \%$ \\
Plastic limit & $13.51 \%$ \\
Plasticity index & $11.16 \%$ \\
Particle size & $\leq 0.5 \mathrm{~mm}$ \\
Specific gravity & 2.71 \\
\hline
\end{tabular}

Table 2 Chemical compositions of lime

\begin{tabular}{ll}
\hline Compositions & Values \\
\hline $\mathrm{Ca}(\mathrm{OH})_{2}$ & $\geq 94 \%$ \\
$\mathrm{CaCO}_{3}$ & $\leq 4 \%$ \\
$\mathrm{MgO}$ & $\leq 2 \%$ \\
$\mathrm{SiO}_{2}$ & $\leq 2 \%$ \\
$\mathrm{~Pb}$ & $\leq 0.4 \mathrm{ppm}$ \\
$\mathrm{As}$ & $\leq 2.71 \%$ \\
Free moisture & $\leq 1.0 \%$
\end{tabular}

through a $0.075 \mathrm{~mm}$ sieve. The chemical composition of lime is determined by X-ray diffraction and material parameters provided by the manufacturer and listed in Table 2 .

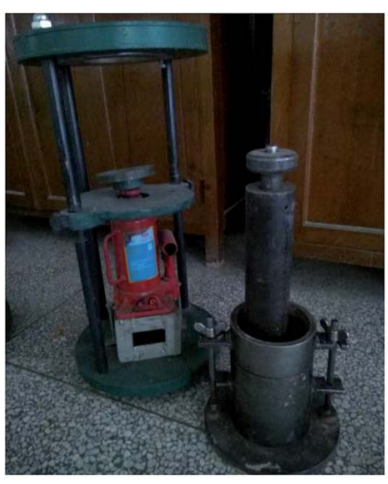

(a)

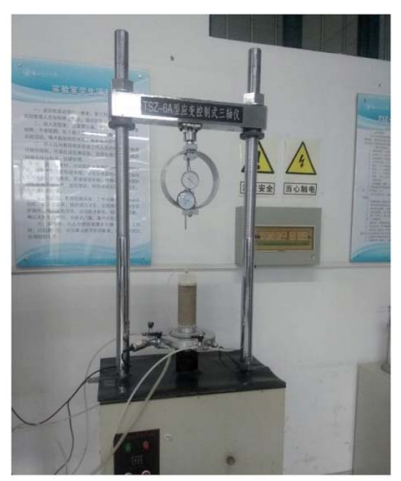

(b)
Fig. 2 Apparatus for (a) compaction test and (b) UCS test. 


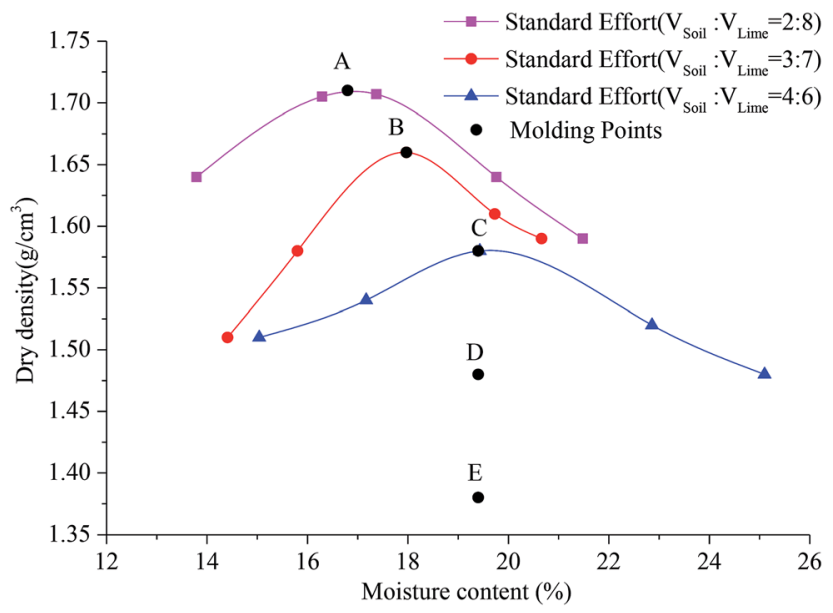

Fig. 3 Moisture content-dry density relation curves of lime stabilized loess and the corresponding molding points.

Table 3 Characteristics of molding points

\begin{tabular}{lll}
\hline Point & $\rho_{\mathrm{d}}\left(\mathrm{g} \mathrm{cm}^{-3}\right)$ & $\omega(\%)$ \\
\hline A & 1.71 & 16.8 \\
B & 1.66 & 17.97 \\
C & 1.58 & 19.4 \\
D & 1.48 & 19.4 \\
E & 1.38 & 19.4
\end{tabular}

\subsection{Specimen preparation}

The lime, loess and water were measured by mass according to the predesignated mix ratios. The loess was first mixed with dry lime thoroughly. The required amount of water was then added to the dry mixture and the mixing process was continued to ensure the uniformity of the mixture. Then the mixture was

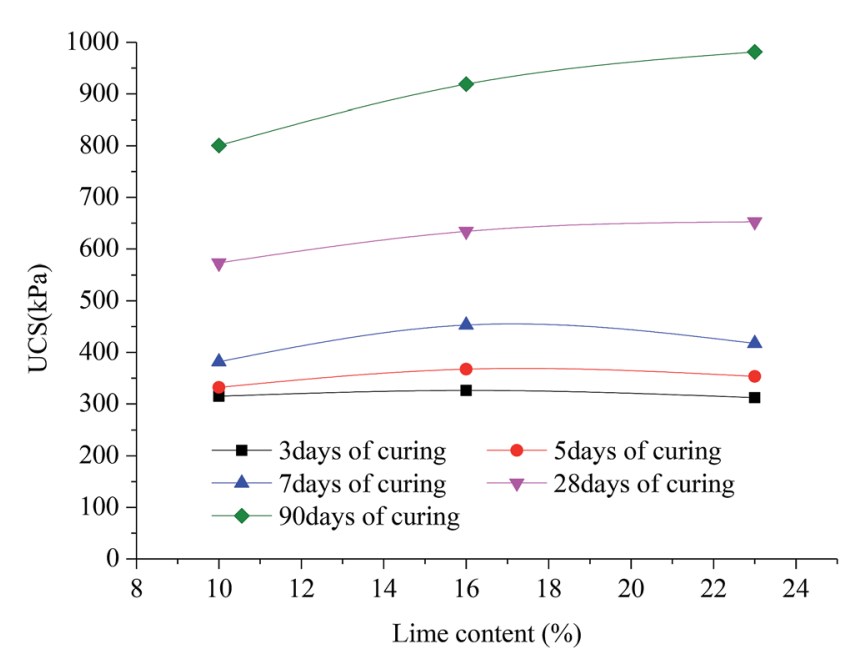

Fig. 4 UCS of lime stabilized loess at molding points A (lime content of $10 \%), B$ (lime content of $16 \%$ ) and C (lime content of $23 \%$ ) under various curing time.

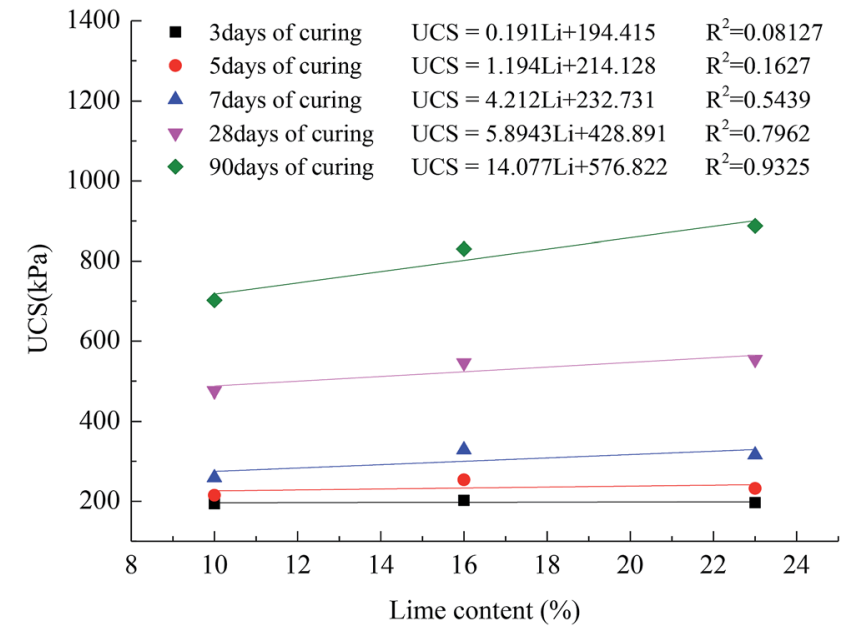

Fig. 5 Effect of lime content and curing time on the UCS of lime stabilized loess at molding point $D$.

sealed in a plastic bag to avoid any moisture loss. The mixture was stored for 24 hours to achieve moisture equilibrium before subsequent compaction. To obtain a uniform lime stabilized loess, the prepared sample was compacted in five layers inside a cylindrical steel mould with $61.8 \mathrm{~mm}$ diameter and $125 \mathrm{~mm}$ height. After compaction, the specimens were extracted from the mould. They were labelled and placed in a covered container. After all specimens were fabricated, they were cured in a humid room with a temperature of $20 \pm 2{ }^{\circ} \mathrm{C}$ and relative humidity above $95 \%$, for 3 days, 5 days, 7 days, 28 days and 90 days, respectively.

\subsection{Test procedure}

2.3.1 Standard compaction test. To obtain the maximum dry densities and the optimum moisture contents of different lime stabilized loess samples, standard compaction tests were performed on all mix ratios in accordance to ASTM D698 (2012). ${ }^{39}$ The apparatus for compaction test is shown in

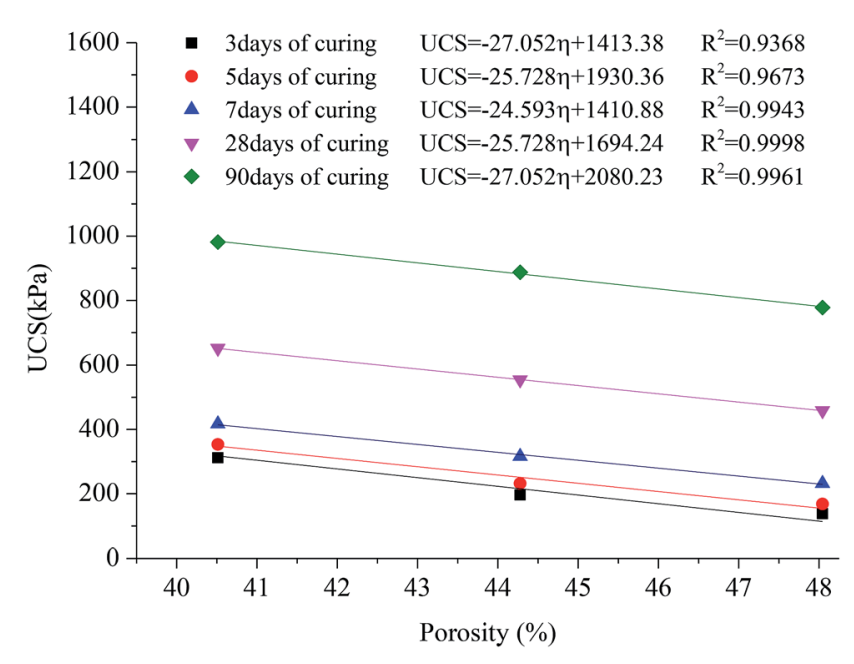

Fig. 6 Variations of UCS with porosity. 


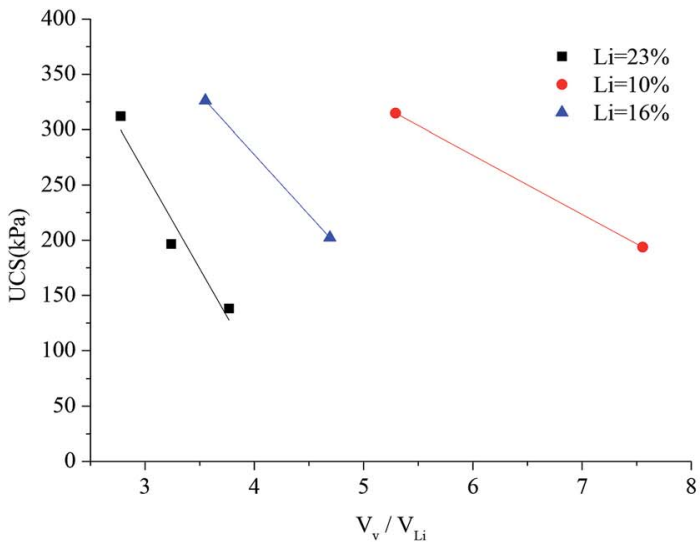

(a)

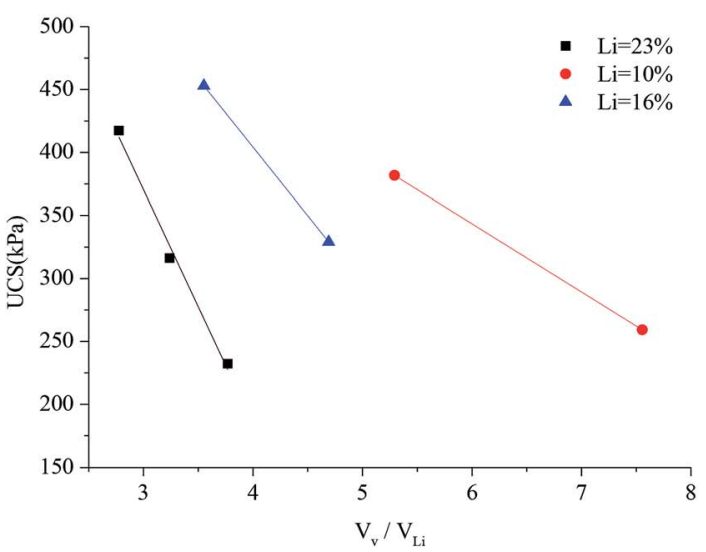

(c)

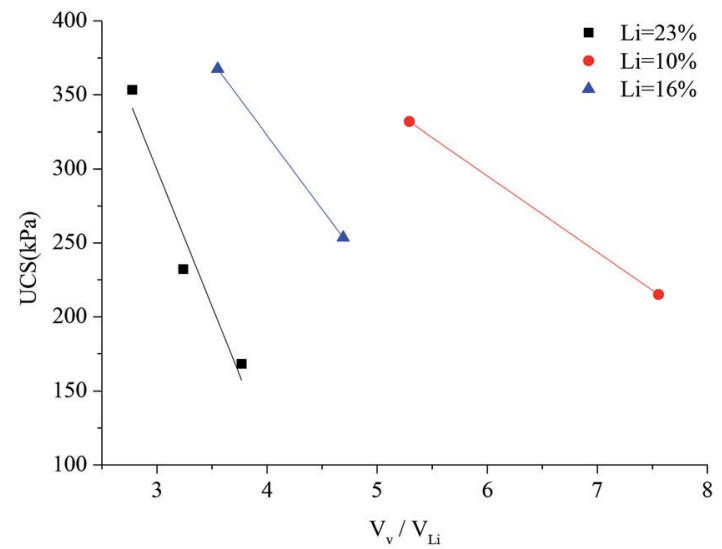

(b)

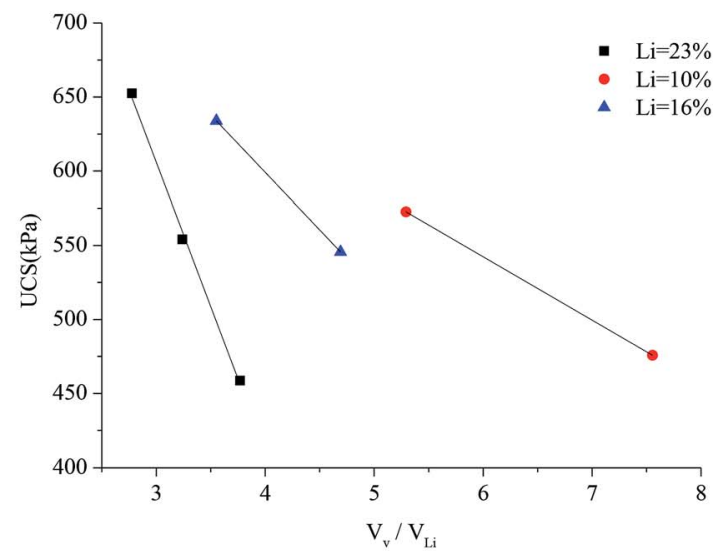

(d)

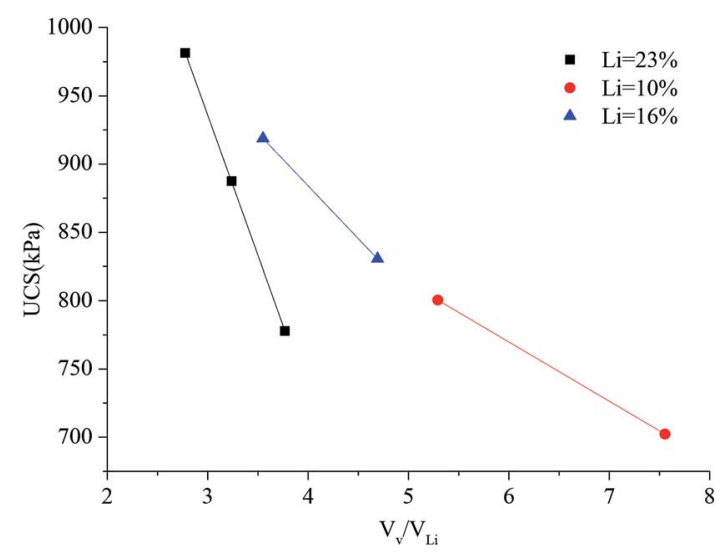

(e)

Fig. 7 Variation of UCS with voids/lime ratio for different curing time: (a) 3 days; (b) 5 days; (c) 7 days; (d) 28 days; (e) 90 days.

Fig. 2(a). Fig. 3 shows the moisture-dry density relationship curves of lime stabilized loess from the standard compaction tests.

2.3.2 Unconfined compression test. Unconfined compression test is one of the widely used laboratory tests to evaluate the strength of geomaterials. The apparatus for UCS test is shown in
Fig. 2(b). To determine the factors (i.e., lime content, porosity and curing time) influencing on the UCS of lime stabilized loess, a series of unconfined compression tests are performed in accordance to ASTM C39 (2012). ${ }^{\mathbf{4 0}}$

The molding points of the lime stabilized loess specimens are also illustrated in Fig. 3. Specimens at points A, B and C 


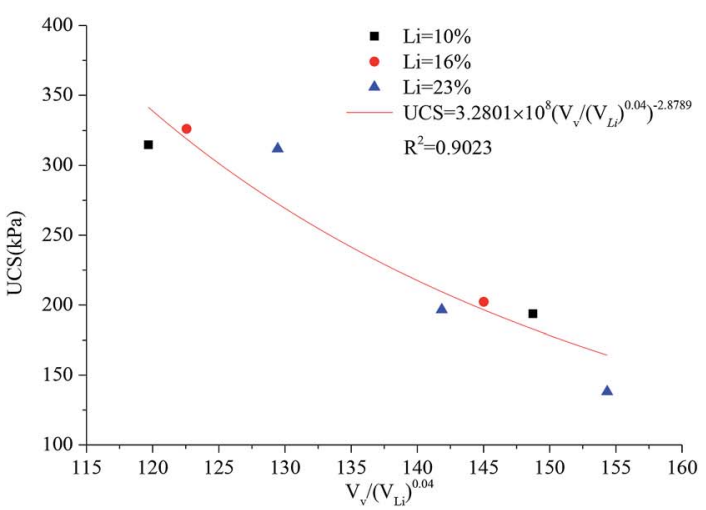

(a)

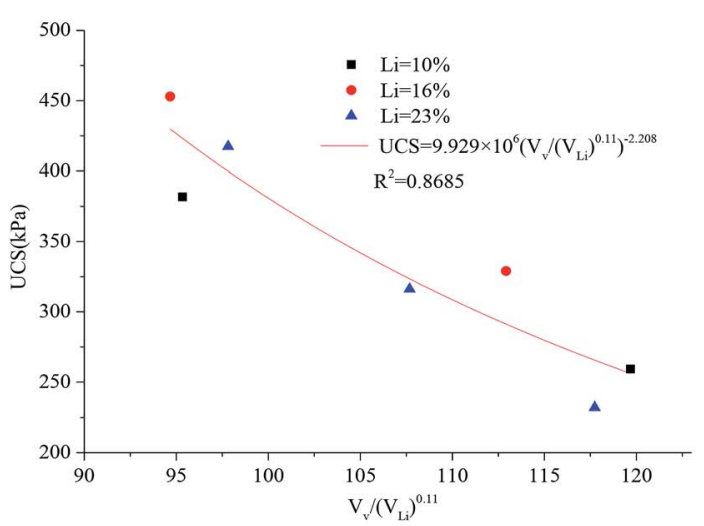

(c)

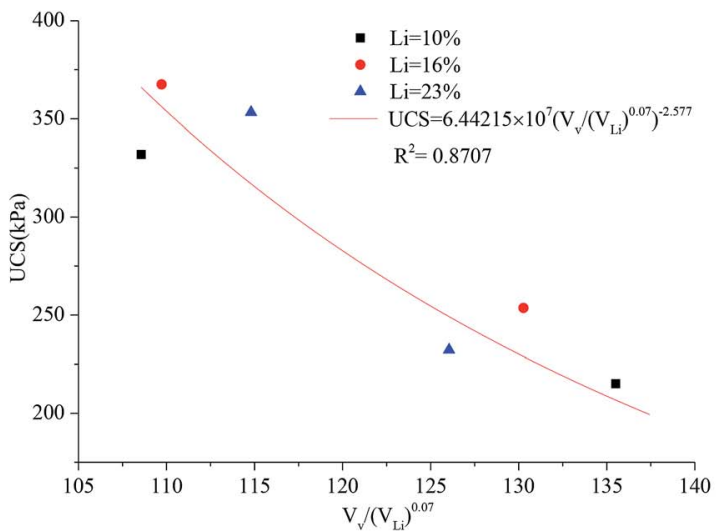

(b)

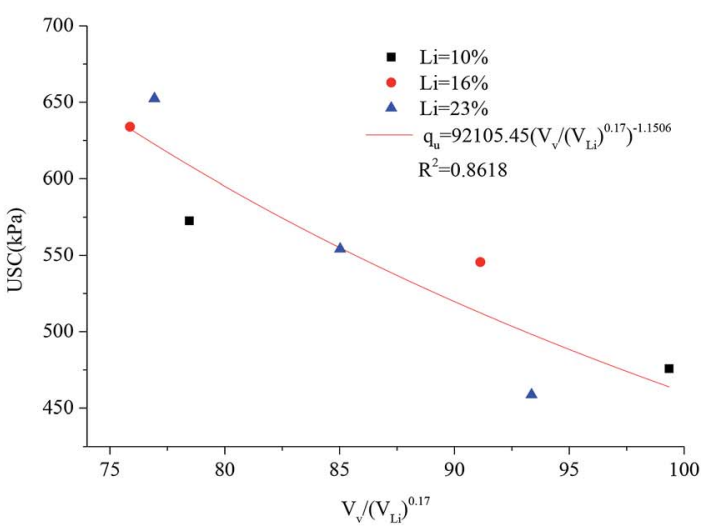

(d)

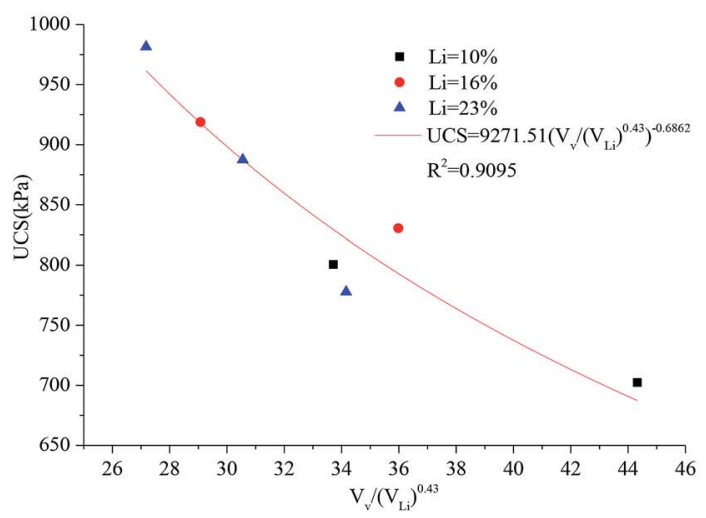

(e)

Fig. 8 Variation of UCS with adjusted voids/lime ratio for different curing time: (a) 3 days; (b) 5 days; (c) 7 days; (d) 28 days; (e) 90 days.

represent the maximum dry density and optimal moisture content of lime stabilized loess with lime contents of $10 \%, 16 \%$ and $23 \%$ (the percentage of dry mass of lime to the mass of the lime-loess mixture), respectively. The corresponding volumetric ratios of lime to loess are $2: 8,3: 7$ and $4: 6$, respectively. At points C, D, E, the compacted specimens have same moisture content but different dry density. Point $\mathrm{D}$ was molded with three different lime contents: $10 \%, 16 \%$ and $23 \%$. While the lime content at point $\mathrm{E}$ is $23 \%$. The dry density, moisture content and molding point of each group are summarized in Table 3. For each scenario, three specimens were prepared and tested, and the mean value of UCS was calculated for further analysis, and it was stipulated that the individual strength of three specimens, molded with the same characteristics, should not be deviated by more than $10 \%$ from the mean strength.

2.3.3 Microstructural analysis. Effect of cementitious materials on the microstructure of compacted mixture has been reported by various researchers. ${ }^{41-48}$ In this study, scanning 


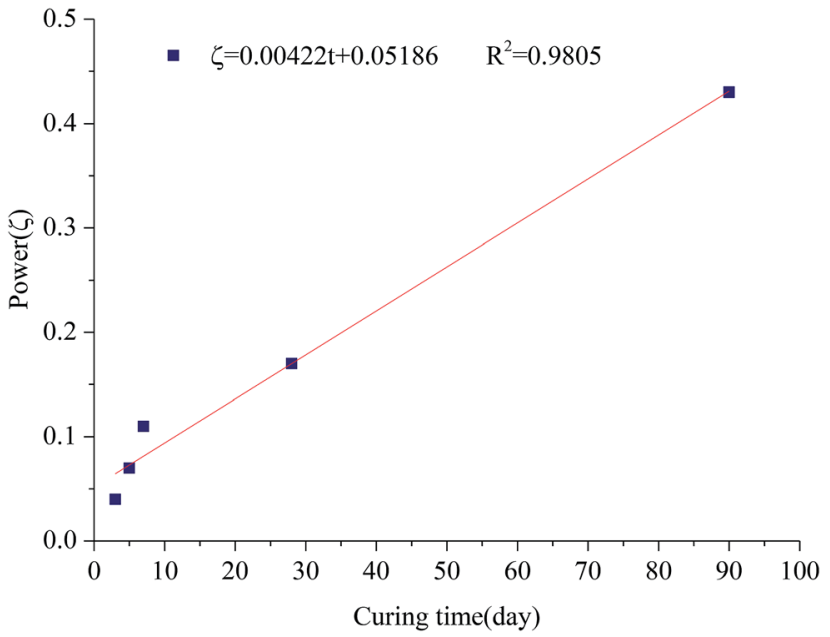

Fig. 9 Variation of power ( $\varsigma$ ) with curing time.

electron microcopy (SEM) was employed to investigate the microstructure of lime stabilized loess (with 10\% lime content) after 7 days, 28 days and 90 days of curing. First, small pieces of samples (about $2 \mathrm{~g}$ in mass) were obtained from the central part of specimens. Then, these samples were oven-dried to remove the moisture in the pores and blown by a blower to remove the dust on the surface. Afterwards, all the samples were sprayed a layer of conductive metal and fixed on the SEM pedestal with conductive adhesive. Finally, microstructural observations were performed on the samples after a vacuum-pumping process.

\section{Results and discussion}

\subsection{Effect of lime content, porosity and curing time on the UCS}

Fig. 4 shows the UCS of lime stabilized loess fabricated at molding points A (lime content of 10\%), B (lime content of 16\%) and C (lime content of 23\%) with different curing time. It can be seen that the UCS of 3 days cured lime stabilized loess almost remain stable for various lime contents. After 5 days and 7 days of curing, the lime content of $16 \%$ leads to maximum UCS of lime stabilized loess. For longer curing time (i.e. 28 and 90 days), the UCS of lime stabilized loess increases with the increasing lime content gradually. It can be also seen from Fig. 4 that the UCS of lime stabilized loess will increase obviously with the curing time for certain lime content.

Fig. 5 illustrates the effect of lime content and curing time on the UCS of lime stabilized loess at molding point D. It can be seen the changing trend of UCS is similar to that shown in Fig. 4 . There is no doubt on the small values of the coefficient of determination $\left(R^{2}\right)$ for short-term curing time from 3 days to 7 days, due to the maximum UCS obtained at lime content of $16 \%$. However, for long-term curing, the UCS can be assumed to be proportional to the lime content. Also, both the coefficient of determination $\left(R^{2}\right)$ for 28 and 90 days seem reasonable. This indicates that for the ultimate state of the stabilized loess (longterm curing), the UCS is likely to exhibit linear growth with lime content.

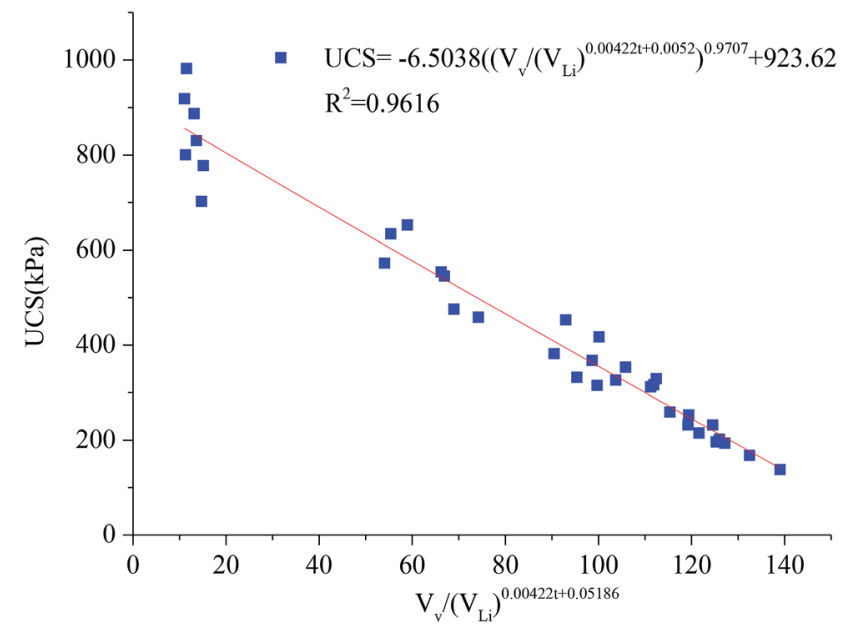

Fig. 10 Correlation of UCS with voids volume $\left(V_{\mathrm{v}}\right)$, lime volume $\left(V_{\mathrm{Li}}\right)$ and curing time $(t)$.

The variations of UCS of lime stabilized loess concerning porosity are shown in Fig. 6. It can be seen that the UCS decreases proportionally with increasing porosity, regardless of the curing time. The variation of UCS with porosity can be contributed to the variation of the amount of interlocking in soil. ${ }^{27,49}$

\subsection{Effect of void/lime ratio on the UCS}

From previous studies, it reveals that the strength of stabilized soil is mainly governed by the amount of stabilizing agent and the porosity of the mixture. ${ }^{50-52}$ Fig. $7(a)-(e)$ present the variations between UCS and the voids/lime ratio for lime stabilized loess with various curing time. The voids/lime ratio can be defined by eqn (1). While the lime volume $\left(V_{\mathrm{Li}}\right)$ and voids volume $\left(V_{\mathrm{v}}\right)$ can be defined by eqn (2) and (3), respectively. ${ }^{29}$ The nomenclatures and measure units for all the parameters are listed in appendix A.

$$
\begin{gathered}
\frac{V_{\mathrm{v}}}{V_{\mathrm{Li}}}=\frac{\text { absolute volume of voids }}{\text { absolute volume of lime }} \\
V_{\mathrm{Li}}=\frac{V_{\mathrm{S}} \rho_{\mathrm{d}}\left(\frac{\mathrm{Li}}{100}\right)}{\mathrm{Gs}_{\mathrm{Li}}} \\
V_{\mathrm{v}}=V_{\mathrm{S}}-\frac{V_{\mathrm{S}} \rho_{\mathrm{d}}\left(\frac{\mathrm{Li}}{100}\right)}{\mathrm{Gs}_{\mathrm{Li}}}-\frac{V_{\mathrm{S}} \rho_{\mathrm{d}}\left(\frac{\mathrm{Lo}}{100}\right)}{\mathrm{Gs}_{\mathrm{Lo}}}
\end{gathered}
$$

It can be seen that the UCS decreases with voids/lime ratio for a certain lime content. However, no clear correlations is achieved between the voids/lime ratio and the UCS of the lime stabilized loess with various lime contents. Moreover, it also shows that the points with the same voids/lime ratio but molded by different combinations of lime content or porosity show distinct strength values.

For a more unified correlation, a power $(\varsigma)$ is applied to the parameter $V_{\mathrm{Li}}$. Fig. 8 shows that a power function can correlate 


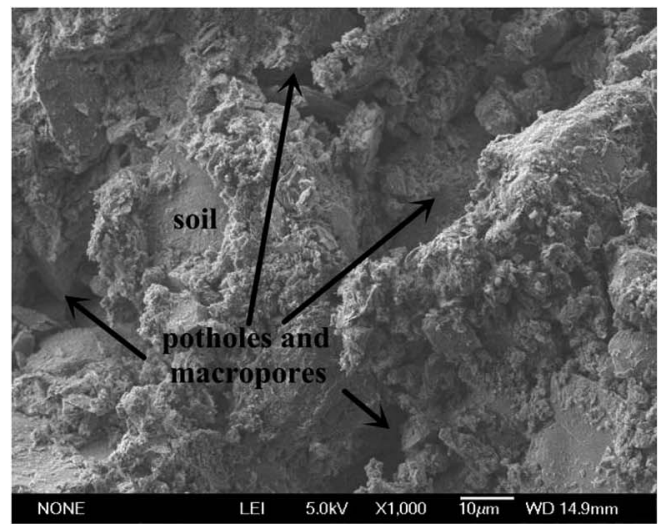

(a) 7 days of curing

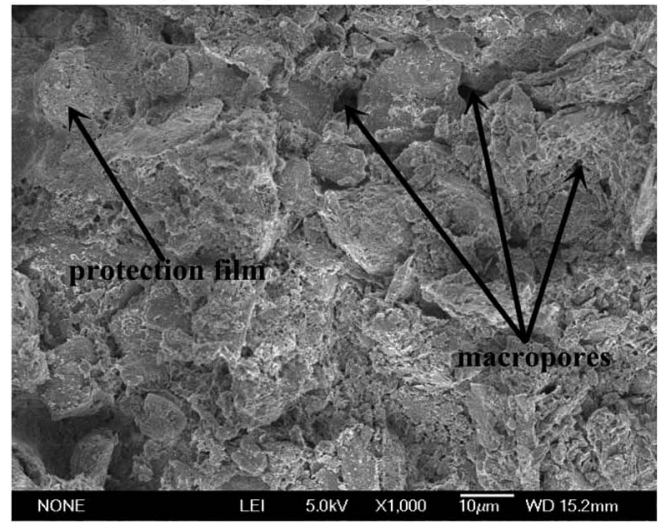

(c) 90 days of curing

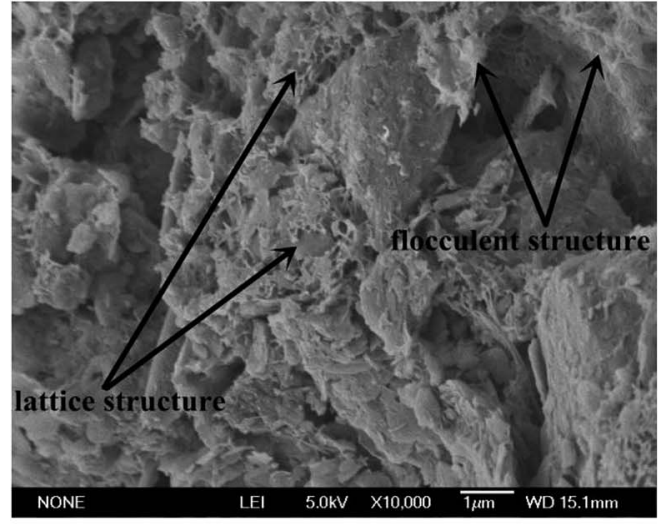

(e) 28 days of curing

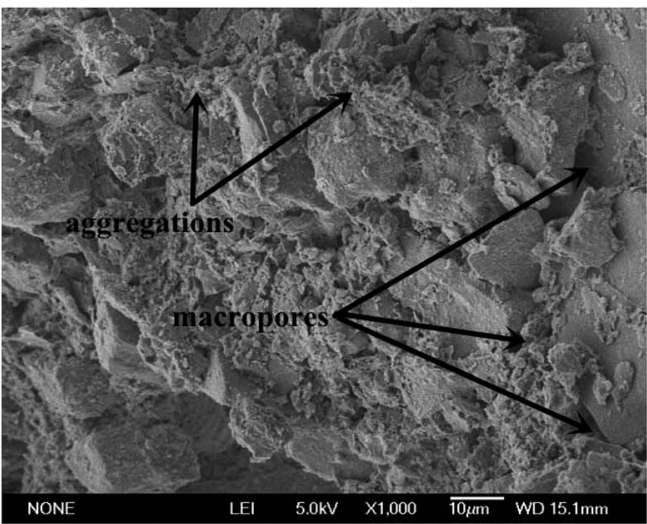

(b) 28 days of curing

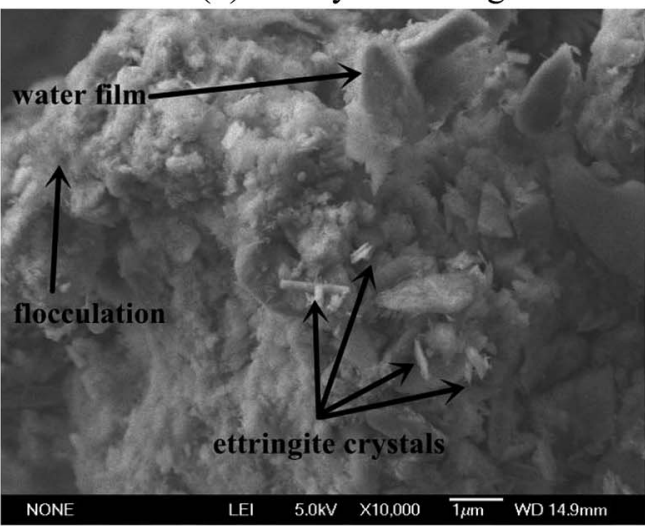

(d) 7 days of curing

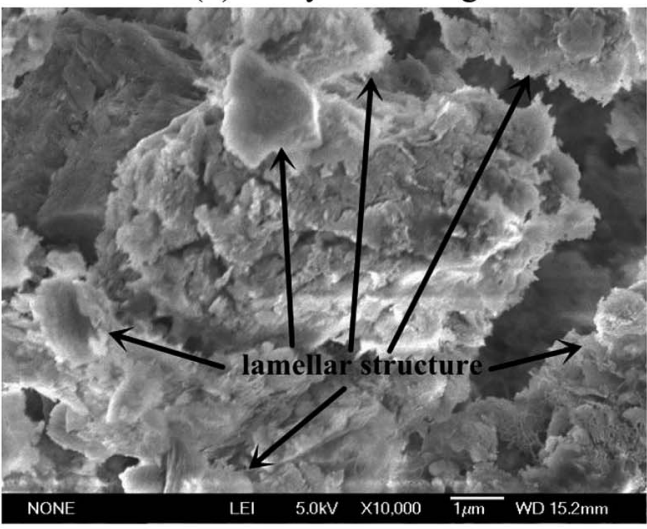

(f) 90 days of curing

Fig. 11 SEM photos of lime stabilized loess samples cured for different time: (a) 7 days ( $\times 1000)$; (b) 28 days ( $\times 1000)$; (c) 90 days ( $\times 1000)$; (d) 7 days $(\times 10000)$; (e) 28 days $(\times 10000)$; (f) 90 days $(\times 10000)$.

UCS and $V_{\mathrm{v}} /\left(V_{\mathrm{Li}}\right)^{\varsigma}$ reasonably (see eqn (4)-(8) for curing time from 3-90 days, respectively). Note that the power $(\varsigma)$ varies with the curing time for lime stabilized loess. It can also be seen that the power $(\varsigma)$ increases approximately linearly with the increase of the curing time, and the best fitting line is shown in Fig. 9. A good correlation $\left(R^{2}=0.9805\right)$ can be observed between the power $(\varsigma)$ and curing time of lime stabilized loess (see eqn (9)).

$$
\operatorname{UCS}(\mathrm{kPa})=3.2801 \times 10^{8}\left[\frac{V_{\mathrm{v}}}{\left(V_{\mathrm{Li}}\right)^{0.04}}\right]^{-2.8789}
$$

$$
\begin{aligned}
& \operatorname{UCS}(\mathrm{kPa})=6.4422 \times 10^{7}\left[\frac{V_{\mathrm{v}}}{\left(V_{\mathrm{Li}}\right)^{0.07}}\right]^{-2.5769} \\
& \mathrm{UCS}(\mathrm{kPa})=9.929 \times 10^{6}\left[\frac{V_{\mathrm{v}}}{\left(V_{\mathrm{Li}}\right)^{0.11}}\right]^{-2.2081} \\
& \mathrm{UCS}(\mathrm{kPa})=92105.45\left[\frac{V_{\mathrm{v}}}{\left(V_{\mathrm{Li}}\right)^{0.17}}\right]^{-1.1506}
\end{aligned}
$$




$$
\begin{gathered}
\operatorname{UCS}(\mathrm{kPa})=9271.51\left[\frac{V_{\mathrm{v}}}{\left(V_{\mathrm{Li}}\right)^{0.43}}\right]^{-0.6862} \\
\varsigma=0.00422 t+0.0052
\end{gathered}
$$

For a further view of eqn (4)-(9), a unique relationship can be achieved for linking the UCS with voids volume $\left(V_{v}\right)$, lime volume $\left(V_{\mathrm{Li}}\right)$ and curing time $(t)$. Fig. 10 shows that when all the points for all curing time, lime contents and dry densities are plotted together, a good correlation can be still achieved between $V_{\mathrm{v}} /\left(V_{\mathrm{Li}}\right)^{0.00422 t+0.0052}$ and the UCS of the lime stabilized loess $\left(R^{2}=0.9616\right.$, see eqn (10)).

$$
\operatorname{UCS}(\mathrm{kPa})=-6.504\left[\frac{V_{\mathrm{v}}}{\left(V_{\mathrm{Li}}\right)^{0.00422 t+0.0052}}\right]^{0.9707}+923.62
$$

Therefore, the use of void volume over volumetric lime content, adjusted by a power (this power can be defined as a function of the curing time) is capable of assessing the UCS of lime stabilized loess.

\subsection{Effect of the curing time on the microstructure of lime stabilized loess}

Fig. 11(a)-(f) present the SEM images $(\times 1000$ and $\times 10000)$ of the lime stabilized loess samples (with $10 \%$ lime content) after 7 days, 28 days and 90 days of curing, respectively. It is observed that an increase in curing time has a great influence on the microstructure of lime stabilized loess. As shown in Fig. 11(a) (1000× magnification), the surface of stabilized loess is occupied by potholes and macropores after 7 days of curing. And the pointedness of particles is also very obvious. In addition, the surface of the sample is covered by a certain number of massive and flake aggregates, which are loosely arranged and scattered in distribution. It also exhibits that the soil particles are wrapped by a thin layer of water, and a few rod-like and needle-like structures can be seen on the surface of some soil particles or aggregations (Fig. 11(d)). According to Zhang et al., cation exchange of calcium occurs mainly in the early curing time of lime stabilized soil, which causes the formation of a little flocculation and the decrease in thickness of a diffuse double layer on the surface of soil particles. ${ }^{53}$ The rod-like and needle-like structures on the surface of sample can be inferred as ettringite crystals which are formed by the presence of gypsum in lime stabilized loess. After 28 days of curing, the number of macropores on the surface of samples decreases, while the volume of aggregations tends to increase (Fig. 11(b)). Moreover, the flocculation structure and lattice structure appeared on the surface of aggregations and soil particles (Fig. 11(e)). After 90 days of curing, the number of potholes and macropores on the surface is greatly reduced. The macropores between aggregations and soil particles are filled by lamellar structures. Also, a protection film was observed on the surface (Fig. 11(c)). The formation of this protection film is due to the setting and hardening of cementitious materials. By comparing Fig. 11(e) and (f), it seems that a small quantity of flocculation structure and lattice structure have developed into lamellar structures with a larger volume. The observations mentioned above suggest that, the longer the curing time, the denser the structure. These differences in fabric among the three samples can be explained by the differences in the development of cementation bond. The cementation products is formed by lime reaction and filled in the voids among particles, leading to a higher density of the stabilized loess. Moreover, the number of cementation products increase with the curing time, which is also the main reason for strength development of lime stabilized loess. For the mechanism of strength development in lime stabilized loess is attributed to cation exchange, pozzolanic reactions and carbonation. ${ }^{54}$ The cation exchange first occurs when lime is added to loess. This process decreases the thickness of the diffuse double layer on the surface of loess particles, which results in the decrease of distance between loess particles and the increase of molecular attraction. Cation exchange of lime stabilized loess is a short-term process and mainly presented as the agglomeration of loess particles, which cause a slight increase in the strength of lime stabilized loess. ${ }^{\mathbf{1 0}}$ Whereas, pozzolanic reactions and carbonation are a long-term and slow process, during which the new cementitious materials are formed and filled in the porosity among loess particles and bonded the soil particles together, and thus greatly increase the strength of lime stabilized loess. ${ }^{20}$

\section{Conclusions}

The paper investigates the strength development of lime stabilized loess based on UCS test and SEM analysis. The following conclusions are drawn: for short-term curing (i.e. 3, 5 and 7 days), the influence of lime content on UCS of stabilized loess is not very obvious. While for long-term curing (i.e. 28 and 90 days), UCS of stabilized loess will increase with lime content. For a certain lime content, UCS of stabilized loess increases obviously with curing time. Based on the experimental results, a linear relationship can be used to correlate the UCS with porosity. Moreover, it was also found that the void ratio and lime content are closely related to the UCS of lime stabilized loess. The relationship between void ratio, lime content, age and UCS can be established using the fitting regression of experimental data. Finally, SEM photographs show the microstructure changes in the lime stabilized loess with the increase of curing time, which reveals the strength development mechanism.

\section{Appendix A}

\begin{tabular}{llll} 
Nomenclature and measure units & \\
\hline $\mathrm{Li}$ & Lime content $(\%)$ & UCS & $\begin{array}{l}\text { Unconfined compressive } \\
\text { strength }\end{array}$ \\
Lo & Loess content $(\%)$ & $V_{\mathrm{S}}$ & Volume of specimen $\left(\mathrm{mm}^{3}\right)$ \\
$V_{\mathrm{Li}}$ & Volume of lime $\left(\mathrm{mm}^{3}\right)$ & $\rho_{\mathrm{d}}$ & Dry density $\left(\mathrm{g} \mathrm{m}^{-3}\right)$
\end{tabular}


(Contd.)

Nomenclature and measure units

\begin{tabular}{|c|c|c|c|}
\hline$V_{\text {Lime }}$ & $\begin{array}{l}\text { Stacking volumes of lime } \\
\left(\mathrm{mm}^{3}\right)\end{array}$ & $R^{2}$ & Coefficient of determination \\
\hline$V_{\text {Soil }}$ & $\begin{array}{l}\text { Stacking volumes of soil } \\
\left(\mathrm{mm}^{3}\right)\end{array}$ & $\varsigma$ & $\begin{array}{l}\text { Exponential of power } \\
\text { function }\end{array}$ \\
\hline$V_{\mathrm{v}}$ & Volume of voids $\left(\mathrm{mm}^{3}\right)$ & $\omega$ & Water content (\%) \\
\hline $\mathrm{Gs}_{\mathrm{Li}}$ & Specific gravity of lime & $\mathrm{Gs}_{\mathrm{L}}$ & Specific gravity of loess \\
\hline
\end{tabular}

\section{Conflicts of interest}

There are no conflicts to declare.

\section{Acknowledgements}

This work was financially supported by National Natural Science Foundation of China (Grant No: 51568044).

\section{References}

1 P. Li, H. Qian and J. Wu, Nature, 2014, 510, 29-31.

2 P. Sun, J. B. Peng, L. W. Chen, Y. W. Yin and S. R. Wu, Eng. Geol., 2009, 108, 153-159.

3 M. Jiang, F. Zhang, H. Hu, Y. Cui and J. Peng, Eng. Geol., 2014, 181, 249-260.

4 Y. Zhang, W. Ye and Z. Wang, Civ. Eng. J., 2017, 3, 1008-1019.

5 F. Ma, J. Yang and X. Bai, Transportation Geotechnics, 2017, 11, 41-56.

6 X. Liu, M. Zhang, H. Zhang, Y. Jia, C. Zhu and H. Shan, Eng. Geol., 2017, 227, 4-11.

7 E. Derbyshire, Earth-Sci. Rev., 2001, 54, 231-260.

8 F. Zhang, G. Wang, T. Kamai and W. Chen, Q. J. Eng. Geol. Hydrogeol., 2014, 47, 201-209.

9 J. Q. Zhuang and J. B. Peng, Bull. Eng. Geol. Environ., 2014, 73, 997-1011.

10 X. Pei, F. Zhang, W. Wu and S. Liang, Appl. Clay Sci., 2015, 114, 77-84.

11 J. Zhuang, J. Peng, G. Wang, J. Iqbal, Y. Wang, W. Li, Q. Xu and X. Zhu, Earth Surf. Processes Landforms, 2017, 42, 915927.

12 Y. Gao, H. Qian, X. Li, J. Chen and H. Jia, Environ. Earth Sci., 2018, 77, UNSP529.

13 J. Peng, F. Wang, Y. Cheng and Q. Lu, Eng. Geol., 2018, 247, 48-57.

14 F. Sariosseiri and B. Muhunthan, Eng. Geol., 2009, 104, 119125.

15 P. Li, H. Li, H. Liu and X. Wang, in Advances in Building Materials, Pts 1-3, ed. L. J. Li, 2011, vol. 168-170, pp. 26782682.

16 Y. X. Yu, Y. F. Jiao, B. Liang and W. Zhang, in Advanced Building Materials, Pts 1-4, ed. G. Li, Y. Huang and C. Chen, 2011, vol. 250-253, pp. 421-424.

17 J. Wang, S. Peng and W. Xie, in Civil, Structural and Environmental Engineering, Pts 1-4, ed. X. Zhang, B. Zhang, L. Jiang and M. Xie, 2014, vol. 838-841, pp. 1302-1308.
18 X. P. Su, Adv. Mater. Res., 2014, 1015, 110-113.

19 X. Y. Liu, Y. H. Yang and G. Y. Xu, Adv. Mater. Res., 2014, 1079-1080, 226-232.

20 M. Zhang, C. Yang, M. Zhao, L. Yu, K. Yang, X. Zhu and X. Jiang, J. Hazard. Mater., 2018, 342, 242-251.

21 K. Yao, H. Xiao, D. H. Chen and Y. Liu, Geotechnique, 2018, DOI: 10.1680/jgeot.18.t.010.

22 K. Yao, Q. Chen, J. Ho, H. Xiao and F. H. Lee, J. Mater. Civ. Eng., 2018, 30, 04018255.

23 K. Yao, N. Li, D. H. Chen and W. Wang, Constr. Build. Mater., 2019, 199, 63-71.

24 K. Harichane, M. Ghrici and S. Kenai, International Journal of Civil Engineering, 2011, 9, 90-96.

25 B. Le Runigo, V. Ferber, Y. J. Cui, O. Cuisinier and D. Deneele, Eng. Geol., 2011, 118, 20-28.

26 A. K. Jha and P. V. Sivapullaiah, Eng. Geol., 2015, 198, 53-64. 27 N. C. Consoli, D. Foppa, L. Festugato and K. S. Heineck, J. Geotech. Geoenviron. Eng., 2007, 133, 197-205.

28 N. C. Consoli, A. V. da Fonseca, R. C. Cruz and K. S. Heineck, J. Geotech. Geoenviron. Eng., 2009, 135, 1347-1353.

29 N. C. Consoli, L. D. S. Lopes Jr and K. S. Heineck, J. Mater. Civ. Eng., 2009, 21, 210-216.

30 N. C. Consoli, L. da Silva Lopes Jr, P. D. Marques Prietto, L. Festugato and R. C. Cruz, J. Geotech. Geoenviron. Eng., 2011, 137, 628-632.

31 N. C. Consoli, A. Dalla Rosa Johann, E. A. Gauer, V. R. Dos Santos, R. L. Moretto and M. B. Corte, Geotech. Lett., 2012, 2, 81-85.

32 N. C. Consoli, A. D. Rosa and R. B. Saldanha, J. Mater. Civ. Eng., 2011, 23, 432-440.

33 N. C. Consoli, C. G. da Rocha and R. B. Saldanha, Constr. Build. Mater., 2014, 69, 301-309.

34 N. C. Consoli, C. G. da Rocha and C. Silvani, Constr. Build. Mater., 2014, 55, 238-245.

35 S. J. Feng, F. L. Du, Z. M. Shi, W. H. Shui and K. Tan, Eng. Geol., 2015, 185, 105-115.

36 Z. Lin and W. Liang, Bull. Int. Assoc. Eng. Geol., 1980, 21, 112117.

37 ASTM D854, 2014 Standard test methods for specific gravity of soil solids by water pycnometer, West Conshohocken, PA, 2012.

38 GB/T50123, 1999 Standard for soil test method, Ministry of Construction, P. R. China.

39 ASTM D698, 2012 Standard test methods for laboratory compaction characteristics of soil using standard effort [12400 $\left.f t-l b f / f t 3\left(600 \mathrm{kN}-\mathrm{m} / \mathrm{m}^{3}\right)\right]$, West Conshohocken, PA, 2012.

40 ASTM C39, 2012 Standard test method for compressive strength of cylindrical concrete specimens, West Conshohocken, PA, 2012.

41 S. Horpibulsuk, R. Rachan, A. Chinkulkijniwat, Y. Raksachon and A. Suddeepong, Constr. Build. Mater., 2010, 24, 2011-2021.

42 H. M. Liu, L. M. Wang and P. Gao, Appl. Mech. Mater., 2014, 527, 25-30.

43 L. Mo, F. Zhang and M. Deng, Constr. Build. Mater., 2015, 96, 147-154. 
44 N. C. Consoli, R. A. Quinonez Samaniego and N. M. Kanazawa Villalba, J. Mater. Civ. Eng., 2016, 28, 04016124.

45 N. Yoobanpot, P. Jamsawang and S. Horpihulsuk, Appl. Clay Sci., 2017, 141, 146-156.

46 C. M. Gomes and A. D. S. de Oliveira, Constr. Build. Mater., 2018, 188, 615-620.

47 K. Yao, W. Wang, N. Li, C. Zhang and L. Wang, Constr. Build. Mater., 2019, 206, 160-168.

48 C. Wu, J. Chu, S. Wu and Y. Hong, Eng. Geol., 2019, 249, 2330.
49 N. Consoli, G. Rotta and P. Prietto, Geotechnique, 2006, 56, 69-72.

50 N. C. Consoli, L. Festugato, C. G. da Rocha and R. C. Cruz, Constr. Build. Mater., 2013, 49, 591-597.

51 N. C. Consoli, R. B. Saldanha, J. E. Correa Mallmann, T. M. de Paula and B. Z. Hoch, Constr. Build. Mater., 2017, 157, 65-74.

52 J. A. Baldovino, E. B. Moreira, R. L. dos Santos Izzo and J. L. Rose, J. Mater. Civ. Eng., 2018, 30, 06018008.

53 F. Zhang, X. Pei and X. J. G. Yan, Geotechnical and Geological Engineering, 2018, 36, 685-696.

54 S. Diamond, Highw. Res. Rec., 1965, 92, 83-102. 